\title{
Portfólio: conceitos básicos e indicações para utilização*
}

\author{
GEORFRAVIA MONTOZA ALVARENGA \\ Professora do Departamento de Educação da Universidade Estadual de Londrina. \\ Coordenadora do Núcleo de Estudos e Pesquisas em Avaliação Educacional \\ geomontoza@sercomtel.com.br
}

\author{
ZILDA ROSSI ARAUJO \\ Bolsista do Núcleo de Estudos e Pesquisas em Avaliação Educacional. Aluna do \\ Programa de Mestrado em Educação da Universidade Estadual de Londrina \\ zilda.r@uol.com.br
}

\begin{abstract}
Resumo
Portfólios de ensino têm sido apontados como ferramentas de avaliação de grande valor formativo e reflexivo nos diversos graus de ensino. Neste artigo, apresentamos um breve referencial teórico, selecionado da vasta literatura disponível, cujo objetivo é identificar a importância do seu uso como amostra de evidências das habilidades, atitudes e/ou conhecimentos e aquisições obtidas pelo estudante durante um espaço de tempo.

Palavras-chave: avaliação formativa, portfólio, ensino e aprendizagem.
\end{abstract}

\section{Resumen}

Portfólios de enseñanza han sido señalados como herramientas de evaluación de gran valor formativo y reflexivo en los grados diversos de la enseñanza. En este artículo, presentamos un breve informe referencial teórico, elegido entre la vasta literatura a disposición, cuyo objetivo es identificar la importancia de su uso como muestra de señales de capacidades, actitudes, conocimientos y adquisiciones conseguidas por el estudiante durante un espacio de tiempo.

Palabras-clave: evaluación formativa, portfólio, enseñanza e apredizaje.

\begin{abstract}
Teaching portfolios have been pointed out as highly valuable educational and reflective evaluation tools at various teaching levels. This article presents a brief selection of theoretical references from the large literature available. Its aim is to identify the relevance of using it as a sample of abilities, attitudes, and/or knowledge and acquisitions achieved by students during a certain period of time.

Key words: formative evaluation, portfolio, teaching and learning.
\end{abstract}

* A pesquisa contou com o apoio financeiro da Fundação Ford e teve a colaboração das alunas-bolsistas Débora Alves Batista e Almira Conelhero Alves Souza. 
Ao fazer uma busca no referencial já construído sobre o tema, percebemos que os educadores não propõem uma definição geral, nem um método determinista para o uso do portfólio, embora concordem que ele seja uma ótima ferramenta alternativa para avaliação.

Em geral, portfólios têm sido descritos como uma coletânea das evidências que documentam o desenvolvimento, as competências e as habilidades do indivíduo (Waterman, 1991). O valor de um portfólio está caracterizado no seu desenvolvimento (Ryan, Kuhs, 1993), especialmente porque o processo envolve a auto-reflexão do aluno, induzindo-o à autoavaliação e oferecendo a oportunidade para sedimentar e ampliar suas aprendizagens.

Crockett (1998), grande defensor da ferramenta, ressalta que portfólios podem ser usados como alternativa para o professor avaliar os seus estudantes, bem como para conduzi-los a uma auto-reflexão e posterior auto-avaliação. $\mathrm{O}$ autor conceitua portfólio como uma amostra de exemplos, documentos, gravações ou produções que evidenciam habilidades, atitudes e/ou conhecimentos e aquisições obtidas pelo estudante durante um espaço de tempo.

Harp e Huinsker (1997, p.224), com idéia semelhante, caracterizam portfólio como "uma coletânea de trabalhos, que demonstram o crescimento, as crenças, as atitudes e o processo de aprendizagem de um aluno". Sendo assim, um portfólio deve incluir, entre outros itens, planos e reflexões sobre os temas importantes tratados em sala de aula, estudos de caso pertinentes aos conteúdos em evidência, relatórios, sínteses de discussões, produções escritas ou gravadas, que devem ser a base para a avaliação contínua e evolutiva do progresso dos alunos em relação ao aprendizado. portfólios

Na mesma direção, Gelfer e Perkins (1998, p.44) afirmam que

são mais que simples arquivos ou uma coleção de performances dos alunos. Um portfólio pode ser considerado como um arquivo em expansão dos trabalhos do estudante. Pode ser estruturado de acordo com a área de interesse, conhecimento, habilidades, temas e progressos diários.

As informações que o compõem podem e devem representar os esforços do indivíduo numa área de estudo determinada e demonstrar sua integração e aplicação no desenvolvimento dos trabalhos.

Kish e outros (1997, p.255) são particularmente enfáticos ao destacar "portfólio como ferramenta de avaliação que convida o aluno a contar a 
história de seu trabalho e a se tornar mais reflexivo sobre suas práticas". Para eles,

é através da voz do aluno que há a troca de experiência em sala de aula e que se determinam as necessidades instrucionais relevantes. É o portfólio que fornece a performance do aluno baseada em muitas provas coletadas em cenários reais. É o portfólio que nutre o pensamento reflexivo.

Os autores são pungentes ao afirmar que

a reflexão reduz a tendência do aluno a ser impulsivo e melhora a capacidade de solucionar problemas. O pensamento reflexivo ajuda o aluno a analisar e debater o assunto, bem como melhora a comunicação. Além disso promove a auto conscientização, forçando o indivíduo a questionar-se. (Kish et al., 1997, p.255)

Percebe-se que uma das maiores vantagens oferecidas pelo uso do portfólio, e sem a qual ele não faria sentido, é o desenvolvimento do pensamento reflexivo. Como bem lembra Rosen (1998), o objetivo da educação é ensinar o aluno a pensar, o que implica conduzir um assunto além da mera aquisição, dando-lhe tratamento cuidadoso e conseqüente para o desenvolvimento de competências e habilidades adrede definidas. A ênfase dada ao elemento reflexivo tem sido destacada também por outros autores como Anson (1994), Arter (1992) e Bushman (1993).

Importa destacar que o portfólio demonstra a performance do estudante num determinado momento, tendo como base documentos coletados em cenários reais, selecionados e justificados quanto aos conhecimentos previstos, exigindo que o professor crie situações para que o aluno reflita sobre o que está explorando, para elaborá-lo adequadamente.

Eichinger e Krockover (1998, p.913), além de destacar portfólios como "coleção selecionada de documentos e outros materiais que demonstrem as atividades escolares, os objetivos e o impacto produzido por esse rol de propostas", evidenciam que as declarações reflexivas são o coração do portfólio.

Kish e outros $(1997$, p.257) tratam também de aspectos de reflexão que podem ser melhorados pelo uso do portfólio, ao mesmo tempo em que explicitam cada um deles.

O primeiro a ser lembrado é o elemento cognitivo de reflexão ligado à capacidade de síntese de informações, a partir da análise e avaliação. Afirmam a importância de se estruturar situações que permitam aos estudantes refletir a respeito de seus pensamentos para entender o motivo do aprendizado ou do não-aprendizado. Além disso, identificar quais habilidades já foram adquiridas para seguir em frente, é primordial. 
Segundo os autores, esse auto-diagnóstico é uma das mais importantes possibilidades que o portfólio apresenta. Muitos instrumentos se prestam a isso, como relatam Herbert (1992), Camp e Levine (1991) e Kish et al. (1997), a respeito do programa Propel de Pittsburgh.

O segundo aspecto destaca o elemento socioemocional de reflexão, situa a melhoria da auto-estima, do autoconceito positivo, da autoconfiança, à medida que os estudantes percebem os próprios progressos. Fraisier e Paulson (1992) relatam que mesmo estudantes que apresentam dificuldades em relação a determinados conteúdos começam a escrever melhor e mostram desejo de compartilhar seus trabalhos documentados no portfólio com os colegas, pois isso evidencia seu sucesso e não seus fracassos

Kish e outros (1997) destacam que o elemento moral de reflexão pode facilitar o questionamento ético que guia as ações das pessoas. Ao incentivar a reflexão moral pode-se disparar $o$ subseqüente desenvolvimento da estrutura pessoal de crenças de cada um. Através dos conteúdos lidos, escritos e/ou documentados o aluno pode começar a reconhecer, a questionar e formar uma visão de mundo. "Isso pode ser criticamente importante para jovens adolescentes que estão tentando entender o mundo, o seu lugar nele e estabelecer hábitos de pensamento" (Camp, Levine, 1991, p.203).

Nunca é demais enfatizar que a reflexão, como forma de pensar criticamente a realidade, de olhá-la com clareza, abrangência e profundidade, é de absoluta importância para o desenvolvimento do aluno. Por isso é importante que se encoraje e se melhore essa habilidade.

Sendo os portfólios arquivos do aprendizado que têm como foco o trabalho dos alunos e sua reflexão sobre os mesmos, parece pertinente afirmar que essa ferramenta pode desenvolver o pensamento crítico e as habilidades que são a base dos processos de tomada de decisões em nossas vidas.

Algumas sugestões preciosas podem ser consideradas ao se iniciar um programa, tendo o portfólio como ferramenta. Crockett (1998) considera que para atender a finalidade à qual se destina é necessário que o professor:

- aprenda sobre portfólio e perceba o que representa para os estudantes elaborá-lo;

- compreenda que existem objetivos e/ou competências a serem atingidos e que podem ser modificados ao longo do caminho;

- decida os tipos de evidências que podem ser usadas pelos alunos como prova ou evidência do aprendizado; 
- prepare os materiais a serem utilizados e auxilie com informações e leituras adicionais para que compreendam e elaborem adequadamente as tarefas propostas. Além disso, esclarecer quais evidências básicas são importantes e quais processos e procedimentos são necessários para documentar as realizações;

- encoraje os estudantes a refletirem sobre suas habilidades, dificuldades, interesses e experiências, estimulando a criatividade;

- seja um facilitador e saiba que construir um portfólio não é tarefa fácil. Requer perseverança e paciência;

- ajude o aluno a refinar suas tarefas e refletir sobre elas e ainda ensine como criar portfólios especiais para projetos específicos;

- auxilie os estudantes a entenderem o caminho que precisam percorrer para atingir os propósitos definidos;

- crie oportunidades para estudantes desenvolverem e compartilharem seus portfólios com colegas, amigos, pais e comunidade por meio de atividades e informações verbais e nãoverbais.

Uma questão que precisa ser colocada refere-se ao arquivamento da documentação ou armazenamento dos trabalhos, de forma que isso não se transforme num amontoado de informações desconexas.

É essencial identificar objetivos, competências, habilidades e conteúdos para o ensino e a avaliação, coletar e arquivar apenas trabalhos relacionados à proposta e que tenham real significado, como prova de desenvolvimento das competências então requeridas.

Para isso, é preciso lembrar que existem tipos específicos de portfólios; portanto, trabalhos específicos a serem destacados, analisados e arquivados. A decisão sobre o que documentar e para que documentar, com certeza, influencia a coleta de trabalhos que comporão a amostra do portfólio. A escolha de um ou mais de um tipo é arbítrio do professor.

Danielson e Abruptin (1997) caracterizam pelo menos três tipos de portfólios, considerando basicamente sua função no processo. Os chamados display, os demonstrativos de trabalho e aqueles cujo objetivo é a avaliação do trabalho durante um determinado período.

Os denominados display são utilizados para documentar as atividades executadas em sala de aula. Por exemplo, fotos sem comentários documentam visualmente as atividades de aprendizagem, mas não o progresso ou o desenvolvimento do estudante. Tornam-se importantes, valiosas, mesmo, no portfólio de trabalho, quando acompanhadas de 
comentários do professor e/ou do aluno, e a serviço de uma avaliação mais rica, diversificada, com vistas à regulação da aprendizagem.

O portfólio de demonstração de trabalho é aquele que mostra os melhores trabalhos realizados pelo estudante. Pode ser escolhido pelo professor, pelo aluno ou por ambos, tendo como critério a melhor performance apresentada. Isso inclui a possibilidade de apresentar apenas trabalhos reescritos.

No que tange ao último aspecto, é preciso esclarecer que, embora ofereça uma noção individualizada da performance do estudante, a avaliação que se pode fazer não é muito precisa. Isso porque só se destaca o melhor do aluno, e quem não acompanhou o processo pode ter expectativas irreais sobre o desempenho. Também não oferecem informações que sirvam como guia para o cotidiano da sala de aula, nem informações de como o estudante chegou àquele desempenho.

Gronlund (1998) lembra que uma das formas precisas de se obter uma documentação congruente e que permita um real acompanhamento é a utilização do portfólio de trabalho, que demonstra o que ocorreu durante o processo de aprendizagem de fatos, conceitos, procedimentos, atitudes e/ou a sua aplicação nas tarefas propostas ou no cotidiano.

Em alguns casos, coletam-se inclusive os rascunhos, corrigidos pelo professor ou pelo professor juntamente com o aluno, que são colocados para análise junto ao trabalho refeito. A análise dá a dimensão do esforço inicial, da aplicação do conhecimento e das habilidades desenvolvidas no processo de crescimento.

Esse tipo de portfólio permite, tanto ao estudante como ao professor, uma visão clara do progresso, além de auxiliar na determinação de novos patamares a serem alcançados.

Resta lembrar que avaliar cuidadosamente os trabalhos, relacionando-os com os objetivos pretendidos e com os progressos, torna esse tipo de portfólio uma verdadeira "jóia", "ferramenta de ouro" para a avaliação.

Carney, Cobia e Shannon (1996) chamam a atenção para a preocupação constante com o acompanhamento do aluno por meio do portfólio. Salientam a necessidade do estabelecimento de critérios para o monitoramento contínuo. Recomendações desses autores incluem indicadores para a auto-avaliação, para análise de reflexões, para demonstração de habilidades, para aplicação do conhecimento. Critérios são elementos importantes e devem compor qualquer proposta avaliativa para ser considerada séria. Os autores sugerem que a avaliação seja efetivada em dois momentos: durante o processo de ensino e aprendizagem, no contexto de sala de aula e ao final do processo, 
analisando-se o crescimento e o desenvolvimento demonstrados pelos alunos e retratados nos documentos arquivados no portfólio.

No processo de avaliação do portfólio, é importante que o estudante tenha informações sobre como será processada. Os autores, em geral, sugerem negociação sobre os níveis de competência necessários ao final de cada episódio de aprendizagem; sobre os processos de seleção, elaboração e organização dos materiais que comporão cada parte do processo; sobre quem terá acesso aos materiais e ao portfólio, entre outros. Auto-reflexão, demonstração de habilidades e competências, aplicação do conhecimento também são elementos importantes que devem ser levados em conta desde o início do processo.

Alguns indicadores gerais podem ser usados para monitoramento (Crockett, 1998), embora outros do arbítrio do professor sejam também válidos. Por exemplo, quanto:

- à organização;

- à documentação e demonstração do conhecimento do aluno sobre o conteúdo desenvolvido;

- à presença de reflexões sobre os temas;

- a evidências que demonstrem como o progresso aconteceu;

- à demonstração do conhecimento obtido e a aplicação do mesmo;

- a reflexões do aluno com os indícios ou indicadores do progresso em aprendizagens factuais, conceituais, atitudinais e procedimentais.

Meisels e outros (apud Gronlund, 1998) sugerem um sistema para coleta de informações baseado na performance e desenvolvido na Universidade de Michigan. Recomendam considerar os objetivos curriculares em várias áreas de conteúdo e domínio, sugerem escolher duas áreas por domínio e coletar materiais três vezes ao ano para, então, analisar como foi o progresso em relação àquelas áreas de aprendizagem. Chamam essas amostras de itens centrais e as consideram como a principal documentação para avaliação. Nada impede que se colete material mensalmente para saber se foram atingidos alguns objetivos, e posteriormente decidir por aqueles que realmente documentem o progresso do aluno.

Gronlund (1998) afirma, oportunamente, que é o pré-planejamento, com base nos objetivos curriculares em uma determinada área ou em áreas afins, que torna o processo de coleta de documentação realmente informativo para a avaliação. 
$\mathrm{O}$ autor cita quatro passos importantes para que o processo de elaboração do portfólio realmente seja eficaz. O primeiro deles antecede o início das atividades desenvolvidas pelos alunos, enquanto os outros podem ter a participação dos estudantes. São eles:

- determinar os objetivos, as competências e habilidades a serem desenvolvidas e avaliadas;

- coletar os trabalhos com intenção e propósito;

- determinar como os trabalhos serão organizados e onde serão arquivados;

- selecionar e avaliar os trabalhos.

A literatura e a experiência nos fazem destacar que o portfólio é um instrumento de aprendizagem, tanto para o estudante como para o professor. Avaliar por meio de portfólios demanda tempo, paciência e prática. Decisões sobre que trabalhos são informativos ou que objetivos são mais importantes para documentar requerem uma certa aprendizagem por parte do professor e do aluno.

É comum entre os autores já citados, especialmente Gronlund (1998), enfatizar que os comentários do professor e do aluno junto às amostras são importantes para explicar e analisar contextos, demonstrar como determinados trabalhos foram desenvolvidos e o que ocorreu durante a execução. Há uma certa insistência na idéia de que o objetivo é demonstrar a extensão da compreensão do estudante a respeito do conteúdo incluído.

Definido o que é um portfólio, suas características, vantagens e etapas para construção, resta ainda saber como orientar o aluno para fazer a sua apresentação. Embora não exista um padrão, algumas pistas podem ser auxiliares importantes para tornar o percurso mais fácil e proveitoso.

A maioria dos autores estudados oferece sugestões comuns ao indicar o formato para a exibição. Destacam a importância de um sumário bem elaborado que oriente, tanto o aluno como o leitor (professores, colegas, pais), para o conteúdo do portfólio, bem como para a localização de determinadas tarefas e/ou produtos. Crockett (1998) sugere a introdução de uma carta ao leitor logo no início, após o sumário, que informe sobre o caminho ou a metodologia que o elaborador do portfólio utilizou para evidenciar as competências e habilidades adquiridas. Além disso, explicitar o formato escolhido para apresentação das atividades documentadas e como elas ilustram o seu desenvolvimento.

Em portfólios de alunos do curso superior, é interessante a inclusão de uma apresentação inicial, que demonstre o conteúdo, os objetivos, as 
tarefas e as atividades que o compõem, para que os colegas e professores tenham uma visão geral do trabalho. Além disso, uma apresentação oral, semelhante às defesas de dissertação ou tese, valoriza, e muito, tanto o trabalho em si como o resultado em termos de aprendizagem obtida pelo aluno, no período. Outro detalhe importante refere-se ao estímulo e à ajuda proporcionada ao aluno para que ele mesmo desenvolva um critério para avaliar e organizar seu próprio portfólio. Em última instância, é o teor da pasta que representa o crescimento e a aquisição do aluno. Aí pode estar o segredo da consecução positiva de uma avaliação formativa.

No tocante a isso, Crockett (1998) lembra algumas categorias para arquivo dos trabalhos. A primeira diz respeito aos trabalhos realizados pelo aluno, mas escolhidos e classificados pelo professor. Embora haja certa polêmica sobre a escolha pelo professor, considera-se que não é uma alternativa inválida, já que o aluno pode retirá-lo a qualquer momento da sua pasta, especialmente para fazer correções e apresentar a nova versão.

Outra categoria relaciona-se às amostras processadas, ou seja, analisadas pelo próprio aluno e já reformuladas. Segundo o autor, essa forma é interessante, pois auxilia o desenvolvimento de um senso de continuidade de projeto a projeto e a habilidade de auto-análise. Além do que, dá poder aos alunos de se tornarem parceiros no processo de avaliação, evitando que assumam o papel de receptores passivos ou que apenas reformulem trabalhos a partir das indicações do professor. O processamento em si não deve necessariamente receber uma nota, mas pode ser apropriado encorajar o aluno por meio do uso de bônus ou penalidade.

Além dessas, outra a ser ressaltada diz respeito aos trabalhos que foram revisados ou reescritos, em razão "[...] das mudanças recomendadas pelo professor e pelos próprios alunos durante a fase de processamento" (Crockett, 1998, p.63).

Sessões de discussão sobre a documentação arquivada, entre os alunos e entre professor e alunos, ao serem instituídas, fazem com que os estudantes tenham oportunidade de expressar sua compreensão a respeito de conteúdos, competências e habilidades. Também permitem que o professor possa dar atenção às áreas em que o estudante apresente defasagens, propondo outras alternativas que favoreçam as aprendizagens pretendidas.

Essas sessões também são importantes para a determinação de novos objetivos. As reuniões são poderosos auxiliares para identificar áreas que necessitam de melhoria, sugerir formas para o desenvolvimento, documentar o crescimento, o desenvolvimento individual, demostrar o potencial de trabalho do estudante e até mesmo para auxiliar o próprio 
estudante a determinar um plano de ação para construir novas habilidades e competências (Gelfer, Perkins, 1998, p.47).

É de bom senso considerar que desenvolver um portfólio demanda tempo e é um processo trabalhoso, tanto para o aluno como para o professor. Isso porque é preciso que não só a coleta, que caracteriza a amostra de trabalhos, como a sua organização sejam reais indicadores das aprendizagens obtidas, para que a avaliação seja justa, embora rigorosa. A tarefa de acompanhar e oferecer feedback é onerosa em termos de cuidado, especialmente no que diz respeito à definição dos critérios que permitirão uma acompanhamento quase que individualizado. Apesar da elaboração demorada e trabalhosa, os benefícios de seu uso superam essa limitação.

\section{REFERÊNCIAS BIBLIOGRÁFICAS}

ANSON, C. M. Portfólios for teachers: writing our way reflective practice. In: BLACK, L. et al. (eds.) New directions in portfólio assessment. Portsmouth: Boynton Cook, 1994. p.185-200.

ARTER, J. A. Portfólios in Practice: what is a portfólio? In: ANNUAL MEETING OF THE AMERICAN EDUCATIONAL RESEARCH ASSOCIATION, San Francisco,1992. Paper presented.

BUSHMAN, L. Takings an integrate approach. Learning, v. 21, p. 22-25, 1993.

CAMP, R.; LEVINE, D. Portfolios evolving: background and variation in sixty-through, twelfth-grade classrooms. In: BELANOFF, P.; DICKSON, M. (eds.) Portfolios: process and product. Portsmouth, N. Y.: Boynton-Cook, 1991. p. 194-205

CARNEY, J.; COBIA, D.; SHANNON, D. M. The use of portfolios in evaluation - revisited. Counselor Education and Supervision, v.36, p.141-143, Dec. 1996.

CROCKETT, T. The portfolio journey: a criative guide to keeping studentmanaged portfolios in the classroom. Englewood Colorado: Teacher Ideas. A Division of Libraries Unlimited, 1998.

DANIELSON, C.; ABRUPTIN, L. An introduction to using portfólios in the classroom. Alexandria: Association for Supervision and Curriculum Development, 1997. 
EICHINGER, D. C.; KROCKOVER, G. H. Developing a faculty portfolio tips and suggestion for science educators. Journal of College Science Teaching, v. 27, n.6, p. 411-415, May, 1998

FRAISIER, D. M.; PAULSON, P. L. How portfólios motivate reluctant writer. Educational Leadership, v.49, p. 62-65, 1992.

GELFER, J. I.; PERKINS, P. G. Portfolios: focus on young children. Teaching Exceptional Children, v. 31, n.2, p. 44-47, Nov./Dez. 1998.

GRONLUND, G. Portfólios as an assessment tool: is collection of work enough? Young Children, v.53, n.3, p. 4-10, May, 1998.

HARP, K. S.; HUINSKER, D. M. Implementing the assessment standards for school mathematics. Teaching Children Mathematics, v.3, p.224-228, Jan. 1997.

HERBERT, E. A. Portfolios and self-assessment. English Journal, n. 81, p.4648, Feb. 1992.

KISH, Cheril K. et al. Portfólios in the classroom: a vehicle for developing reflective thinking. The High School Journal, v. 80, p. 254-260, Apr./May 1997.

RYAN, J. M.; KUHS, T. M. Assessment of preservice teachers and the use of portfólios. Theory into pratice, v.32, n.2, p. 75-81, 1993.

ROSEN, D. D. Problem solving and reflective thought: John Dewey, Linda Flower, Richard Yong. Journal of Teaching Writing, v. 6, n.1, p. 69-78, 1998.

WATERMAN, M. A. Teaching portfólios for summative and peer evaluation. In: AMERICAN ASSOCIATION FOR HIGHER EDUCATION CONFERENCE ON ASSESSMENT FOR HIGHER EDUCATION, 6, San Francisco, 1991. Paper presented.

Recebido em: junho de 2005

Aprovado para publicação em: setembro de 2005 
